This item was submitted to Loughborough's Research Repository by the author.

Items in Figshare are protected by copyright, with all rights reserved, unless otherwise indicated.

\title{
Mobilising recipiency: child participation and 'rights to speak' in multi-party family interaction
}

PLEASE CITE THE PUBLISHED VERSION

http://dx.doi.org/10.1016/j.pragma.2013.01.012

PUBLISHER

(C) Elsevier B.V.

VERSION

AM (Accepted Manuscript)

LICENCE

CC BY-NC-ND 4.0

REPOSITORY RECORD

Butler, Carly W., and Ray Wilkinson. 2019. "Mobilising Recipiency: Child Participation and 'rights to Speak' in Multi-party Family Interaction”. figshare. https://hdl.handle.net/2134/13329. 
This item was submitted to Loughborough's Institutional Repository (https://dspace.lboro.ac.uk/) by the author and is made available under the following Creative Commons Licence conditions.

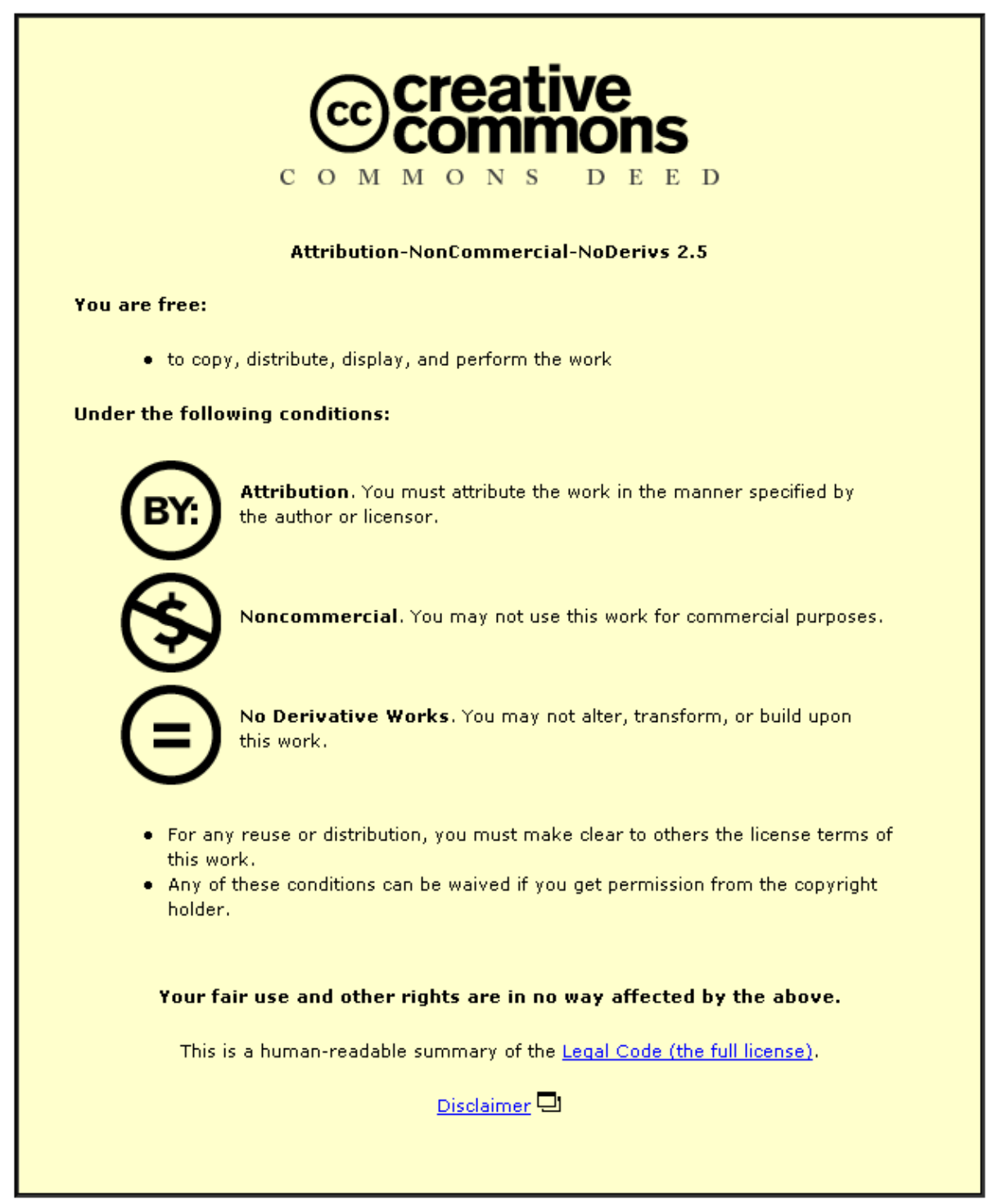

For the full text of this licence, please go to: http://creativecommons.org/licenses/by-nc-nd/2.5/ 


\title{
To appear in Journal of Pragmatics \\ *Final Author Version*
}

\section{MOBILIZING RECIPIENCY: CHILD PARTICIPATION AND ‘RIGHTS TO SPEAK' IN MULTI-PARTY FAMILY INTERACTION}

\author{
Carly W. Butler (Loughborough University) \& Ray Wilkinson (Sheffield University)
}

\begin{abstract}
This paper discusses a child's participation in multiparty family interaction. Drawing from video-recordings of a family Christmas event, we examine instances where a child produces an initiating action that is unsuccessful at first in gaining the recipiency of the addressee(s). We show how for the child a regular issue might be not simply pursuing a response, but more generally mobilizing the adult addressee's recipiency and engagement. The analysis describes the methods by which the child attempts to mobilise recipiency, how these attempts are responded to by the adults in the interaction, and how the child pursues recipiency when it is not gained in the first instance. Drawing on these empirical findings we examine the notion of children's 'rights to speak' in interaction, in particular reconceptualizing it the along the lines of 'rights to engage'. The paper contributes to understandings about children's communicative competence, as well as identifying more generic aspects of the management of multiparty interaction.
\end{abstract}

Keywords: Children; family; conversation analysis; multiparty interaction

\section{Introduction}

Multiparty interactions involve a number of practical issues for members in terms of participation and associated rights to speak. Multiple participants can take part in collective conversation with the possibility of all present members taking turns as speakers and/or recipients in a focused encounter. Alternatively, two or more interactions may be carried out in parallel, for example, by schisming when a collective encounter splits into two smaller engagements (Egbert, 1997; Sacks, Schegloff and Jefferson, 1974). In some instances speakers are organised into parties rather than single persons (Schegloff, 1995). This means that rather than speaking as individual persons, a speaker may talk as a member of a social group (such as a couple) or an interactionally produced grouping (such as co-tellers of a story). A classic, institutional, example is the organisation of talk in the classroom in which members are divided into two parties - teacher and pupils. The organisation of members into speakers and/or parties can alter on a turn-by-turn basis, with each variation having implications for 
participants' speaking and listening rights and responsibilities, and for how social activities are accomplished.

Initiating an action in a multi-party interaction may involve more interactional work than in two-party interaction in terms of the speaker first gaining the recipiency of another participant and then delivering their turn in such a way so as to get a response (cf. Ford and Stickle, 2012). In most cases these two activities will be merged, i.e. by starting to speak (in the clear) and doing so with a turn which is hearably delivered for a particular recipient or recipients, a speaker both claims the floor and implicitly claims a right to be attended to by the targeted recipient(s). Conversation analytic research has demonstrated how people monitor ongoing interactions for possible turn transition places, and can utilize a wide range of resources and practices (e.g. gaze, gesture, body position and talk) as methods for establishing a state of mutual attention necessary for the successful initiation of a course of action (e.g. Goodwin 1981; 1986). For instance, in-breaths and changes in physical orientations can be used by speakers to demonstrate that they are about to launch a turn (Schegloff, 1996a; Streeck, 1995). These methods require an acute and fine-tuned monitoring of talk-in-interaction (i.e. other's gaze, gesture and talk), and an ability to use these same resources.

Children may, arguably, be understood to occupy a somewhat special space within adult-dominated multi-party interaction. While, like adults, they need to attend closely to the organisation of members and interactions in order to secure participation within the conversation(s) and to recognize and produce relevant methods for establishing a space to initiate talk, children face an additional challenge of managing their rights not just as speakers, but as children - with all the expectations and limitations that this may entail. Shakespeare (1998) suggests that children are treated as less than full-members, and their relative lack of competence is oriented to by adults (ordinary full members) within interaction (also see Forrester, 2010; Hutchby, 2005; 0’Reilly, 2006). The notion that children's membership as children is omnirelevant in terms of their participation in interactions with adults is, to a large extent, a common-sense one - with idioms such as 'children should be seen and not heard' hinting at a distinct set of norms around children's limited participation by virtue of their position in a stage-of-life hierarchy. However, the idea that children's membership is always potentially relevant in terms of 
how and when they get to take a turn at talk has a more specific relevance in empirical studies of interaction.

As Schegloff (1989) suggested, children need to learn that 'talk-by-one-person is ... an outcome, which it takes the whole assemblage to produce' (p140). This involves learning to listen while talking or talk while listening during overlapping talk; recognizing that people can still be 'talking' even if they are silent (for instance in trying to remember a name), or have finished a sentence (e.g. in telling a story); and that talk may be interruptive if it comes before a sequence (such as making arrangements) is complete. The learning of such matters is part of the child's development of communicative competence (Ervin-Tripp and Mitchell-Kernan, 1977), and their entry into the cultural worlds to which they are born. It may be that this aspect of communicative competence continues to develop beyond the early years of childhood. However, the nature of children's participation is not merely a matter of them 'learning' how to take part in interaction -membership as children can be made relevant by both adults and children in the course of situated interaction (Aronsson and Gottzen, 2011; Butler and Fitzgerald, 2010; Forrester, 2002). In this respect, while children develop practices associated with taking part in interaction, they do so as members and coproducers of the adult-child relationship, as one of the multiple and fluid cultural worlds into which they are born.

A child's position within adult-focused interaction is generally understood to be one in which they have limited rights to speak ${ }^{1}$. For example, in his analysis of a story told by a child, Sacks (1972: 343) observes: 'I begin, roughly and only as an assumption (though naively, the matter is obvious), by asserting that kids have restricted rights to talk'. Sacks then goes on to discuss an utterance such as 'You know what, Daddy?' as a solution to these restricted rights in that with the expected response of 'what' by the parent, the child gets a go-ahead in which they not only have access to a third slot within an interaction, but they actually have an obligation to speak next ${ }^{2}$. These

\footnotetext{
${ }^{1}$ A notion that was perhaps more salient in the past when children were supposed to be 'seen and not heard'. Some have argued for a cultural shift in terms of children's rights, which has altered the way children's agency is oriented to by both parents and children in the family home (e.g. Aronssen and Cekaite, 2011).

2 For discussion of Sacks's observation see Forrester, 2010; Hutchby, 2010.
} 
observations by Sacks were not, however, based on data from talk-in-interaction and there has subsequently been little systematic empirical examination of whether and how an orientation to limited speaking rights manifests itself in actual adult-child interaction. Moreover, are these rights more or less relevant when it is not simply an issue of a child getting a parent's attention in two-party interaction, but of a child managing the multiple involvements and concurrent activity that is found in multiparty interaction?

This paper forms part of an ongoing investigation into the issue of children's participation within family interactions and the ability to engage others in interaction. As such, rather than focus on a specific practice, we discuss a number of methods used by participants in negotiating participation and engagement in interaction. We focus primarily on instances where a child produces an initiating action (i.e. an action that launches a new sequence or course of action) that is unsuccessful at first in gaining the recipiency of its addressee(s) either because the adults concerned disattend it or they suspend its relevance through a directive such as 'wait'. Through cases such as these we show how for the child in adult-dominated interaction a regular issue might be not simply pursuing a response to a first pair part (FPP) (see Stivers and Rossano, 2010), but more generally mobilizing the adult addressee's recipiency and engagement. Drawing on these empirical findings we go on to examine the notion of children's 'rights to speak' in interaction, in particular reconceptualizing it the along the lines of 'rights to engage'. In this reconceptualization we draw on Sacks' (1995: 683) observations concerning the distinction between:

، "having the floor" in the sense of being a speaker while others are hearers, and "having the floor" in the sense of being a speaker while others are doing what they please. One wants not merely to occupy the floor but to have the floor while others listen'.

Here it is the child's ability to have the floor not simply in terms of 'speaking' or 'talking' but rather in the sense of mobilizing recipiency and engaging others in a particular course of action that is the focus of our analytic attention, including how the child's attempts to do so are treated, and often disattended or resisted, by the adults around him. 


\section{Data}

The data are from a Christmas day celebration with four family members - a five year old boy (Fredrick), his mother (Nina), father (Julian) and grandmother (Jean). Jean does not live with the family and is visiting for the Christmas celebrations. It is a tri-lingual family. While all members speak English, Julian and Jean are native French speakers and Nina is a native German speaker. Fredrick has a fluent understanding of all languages, but primarily speaks in English. When all parties are talking together (or when all parties are assumed to be overhearing), the talk is usually carried out in English. Jean and Julian regularly speak to one another - and occasionally to Fredrick - in French; whilst Nina speaks in German only to Fredrick. While the code-switching in this family is clearly closely tied to how the family produce and organise multiparty interactions, this is the subject of further research and will not be examined here.

Recordings were collected as part of a larger study looking at family interactions. The Wagner family were provided with a video camera for a few weeks and invited to record their interactions whenever they wanted. The collection of recordings includes family mealtimes, television watching, bedtimes, getting ready in the morning, and Christmas celebrations. The family received a copy of all recordings and consented to all material being able to be used for research purposes. In total, around ten hours was collected from the Wagner family. Data was transcribed using Jeffersonian conventions (Jefferson, 2004) to represent the audible aspects of the interaction, but due to videorecorded nature of the data and the centrality of gaze and gesture for the participants themselves in identifying recipients and monitoring concurrent activities and engagements, much of the analysis was conducted through repeated viewing of small sequences of action.

As the family were able to keep a copy of all recordings, they were especially keen to capture their Christmas celebrations from a 'fly-on-the-wall' perspective. Each of the four examples examined below involves an aspect of a Christmas gift-giving episode which weaves throughout the video-recorded interactions produced by this family. The episode is one that is culturally specific as well as being unique in terms of the social order and social practices of this particular family. We might expect that the 
membership of a child as a child may be particularly relevant because of the nature of the activity, in that a child's excitement and enthusiasm is often a marked feature of Christmas activity and gift-giving in particular. Across the episode Frederick's excitement is visible in his talk and embodied actions, as well as being verbally noticed and managed by the parents (in data not shown in this paper). Furthermore, Frederick takes a special interest throughout the episode in progressing the gift-giving activity something that is evident in the examples we discuss. While the specific cultural and ritualistic elements of this episode shape, and are produced and renewed by, the action that takes part within it (see Heritage, 1984); the analysis highlights practices that have a more generic relevance to adult-child interaction, and interaction more broadly.

\section{Analysis}

The gift-giving episode we focus on is an extended encounter that is roughly patterned in a recurring series of gift allocation, gift opening, and displays of appreciation with the members seated around the Christmas tree. However, participants can and do move around during the episode, and attention can and does waver between the on-going relevance of gift-giving and other activities. For instance, one's admiration of a gift can lead to an extended discussion about the gift or gift-giver. Not all members are treated as recipients of a speaker's action at all moments, and there are numerous shifts in the engagement patterns. This particular type of episode is somewhat different to what Schegloff and Sacks (1973) described as an 'ongoing state of incipient talk' in that there are ongoing shifts in the participation frameworks (see Goffman, 1981). Lapses in talk could be considered in terms of lapses in the collective interaction, but these are broken up by smaller sequences of interaction involving two or three out of the four members (see Schegloff, 1995). In this respect, the overall activity of gift-giving is incipient while 'current' and concurrent activities are weaved through this. The possibilities for and organisation of participation is therefore fluid throughout the episode, making relevant Rae's (1991) emphasis on participation frameworks as activity ('frame-work') rather than structures, involving the 'design of conduct in the light of, or to address or change, the relevancies and opportunities of the moment' (p. 255).

There is, then, a sense of focused encounters embedded in a broader focused encounter (see Goffman, 1961), and each member is always potentially a participant within any 
number of encounters. As such, each member could be said to be in an ongoing state of incipient recipiency for talk, in that they could be selected as a recipient in the course of a separate interaction being initiated. This pattern of interaction seems fairly standard for family interactions, and multi-party interaction in general. There has, however, as yet, been little research on the methods through which interaction is managed in such situations.

Given the fluidity with which participation and interactions can shift in such contexts, children need not only to attend to their rights within an ongoing interaction (i.e. in terms of turn-taking rules or norms), but their rights to initiate an interaction or sequence of action within an interaction with one or more members and their recipient's responsibilities as a recipient. Successfully initiating a sequence of action requires that the intended recipient(s) is able to attend and respond to the speaker. This involves an attention to the organisation of members, and to sequence and activity e.g. are the intended recipients currently engaged in some other interaction, and is this an appropriate sequential position to initiate a new action sequence? The outcome of any sequence initiation is contingent upon these matters.

\subsection{Acceding to, and disattending, bids for recipiency}

In the most straightforward of examples, children's initiating actions are responded to in the next turn by their intended recipient. The recipient is both available to engage with the initiating action, and there is a 'slot' within the interaction that the initiating action can be positioned within. In Extract 1, Jean has left her seat to hug and kiss her adult son Julian for the gift she just received. Nina is on her way out of the living area and toward the kitchen. Fredrick sees her leaving and summons her (line 4, see figure 1a), with this pre-sequence explicitly making a bid for her recipiency (see Schegloff, 2007). In response to this summons, Nina stops and pivots back towards Fredrick, at which point he launches his request for them to 'open another one' i.e. another present (line 8, Figure 1b). Nina responds with an affirmative response (line 10) which gives Fredrick the go-ahead for his proposed next action.

\section{Extract 1}


[WagHDSeg2_XmasTree_2300-2437_Cookbook]

1 Jean: I'm going to o:pen $i[t$.

2 Julian: [A- an'

3 Jean: $\quad{ }^{\circ} \mathrm{Mm}^{\circ}$ [( (Kiss sound))

4 Fredrick: [Wha- (..) ${ }^{\text {[a] }}$ ah M[a:ma? ]

5 Julian:

6 (Jean) :

7 Julian:

8 Fredrick:

9 Julian:

10 Nina: Yes? You can open ano:ther [one.

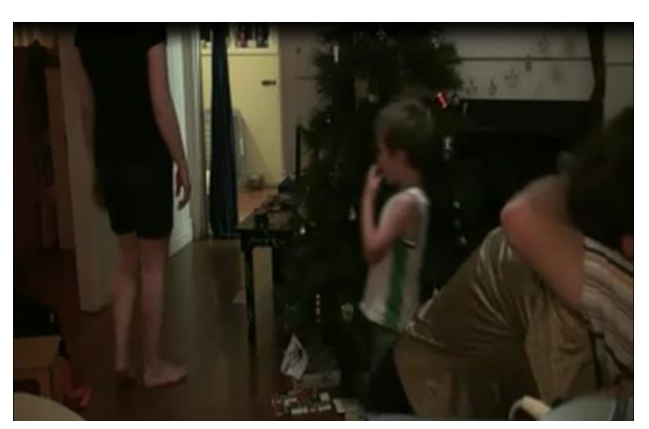

Fig 1a: 'Wha- (.) a Mama?' (L4)

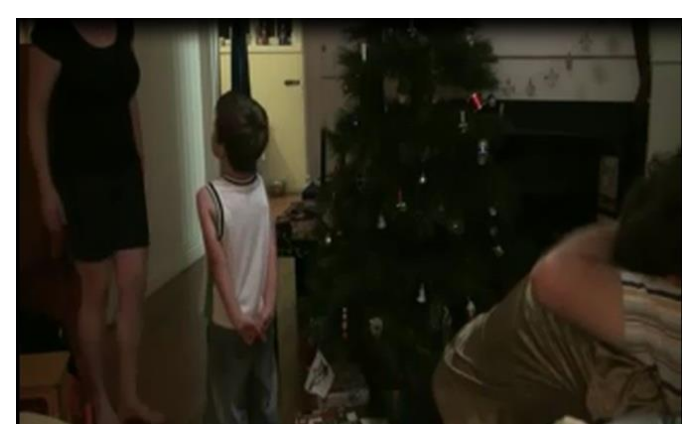

Fig 1b: 'Can we open another one?' (L8) 
At the point of Fredrick's initiation, the party has effectively broken into two parts, with Jean and Julian interacting whilst Nina and Fredrick are each nonengaged. Although Nina is clearly on her way to leaving the room, Fredrick's summons is successful in changing her physical course of action and securing her recipiency. Their engagement with one another therefore runs in parallel, and non-competitively, with that of Jean and Julian. While there are no obvious troubles in the initiation and progression of this concurrent engagement, the engagement is initiated by Fredrick through specific interactional practices by which he actively mobilises Nina's recipiency. He monitors Nina's action to observe she was not engaged with Jean and/or Julian; he moves towards her to close the physical space between them; and he restarts his summons to include the address term 'Mama' to seek Nina's attention (line 4). Nina needs summonsing because she is on her way out of the room and whilst unengaged in interaction, is not clearly 'available' as a recipient. Fredrick needs then to mobilize her recipiency as a first step in establishing a state of mutual engagement.

This first example, while straightforward, demonstrates some of the practical issues that arise out of multiparty interaction. First, initiating an action involves monitoring the engagements of others. Second, securing recipiency may take extra work because of the physical movement and concurrent engagement of others. Third, monitoring and securing recipiency involve identifying transition relevant places at the completion of sequences of action - not simply after a prior turn at talk. For the recipient of an initiating action, the issue is responding in the context of other concurrent interactions.

Our particular interest is in instances where these multiple constraints on initiating actions are shown to be relevant for what transpires when a child attempts to initiate a course of action, and in particular in the methods involved in mobilising recipiency. While Fredrick had no trouble in securing Nina's recipiency in Extract 1, the remainder of our examples involve cases where initial bids for recipiency are at first unsuccessful and recipiency is then pursued. 
One context in which we observe this pursuit is where the targeted recipient was engaged in an ongoing interaction with another person, as in Extract 2 below. The extract begins at the beginning of the recording. Nina is off camera to begin with, having started the recording. Fredrick is completing an apparent request to his father to put a large box onto the ground (line 1). He then requests permission from Nina to open the box as she moves toward him (line 15), but a response is delayed as Nina extends her engagement with Julian (line 16 and following).

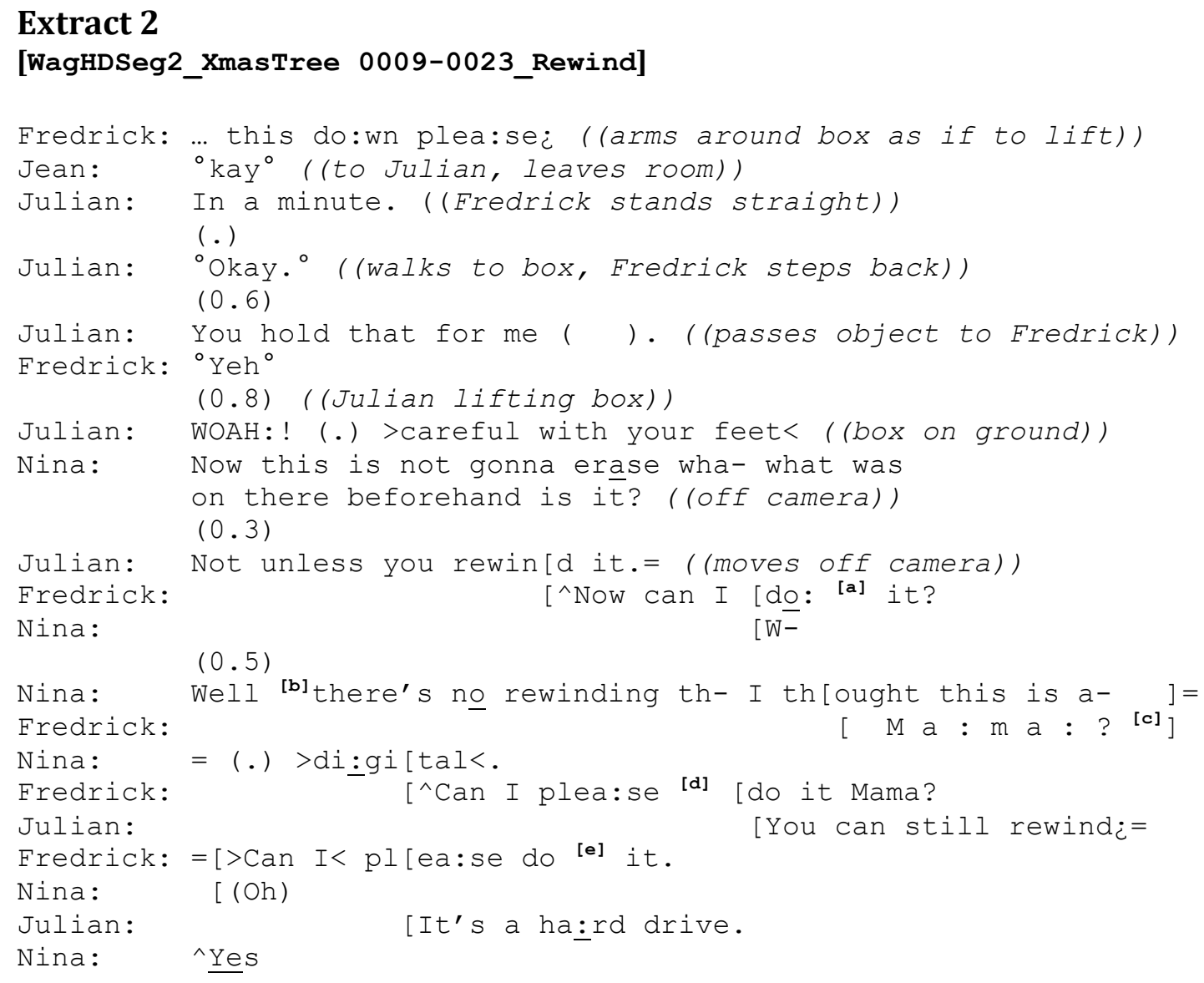




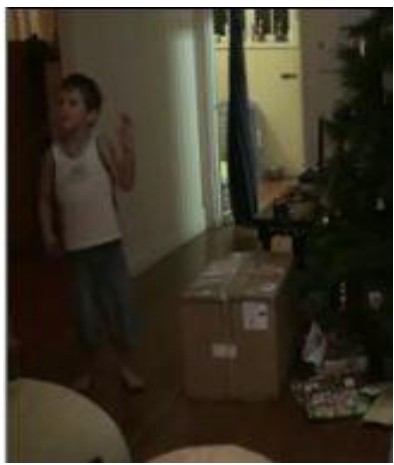

Fig 2a: Now can I do it? (L15)

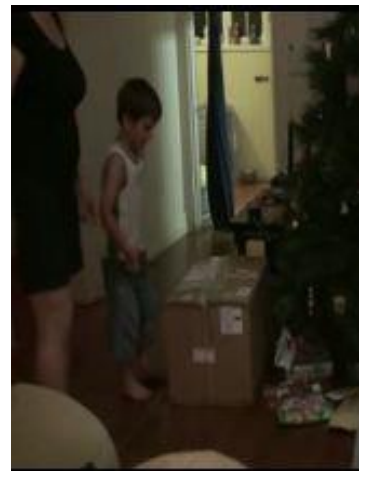

Fig 2b: Well there's no rewinding (L18)

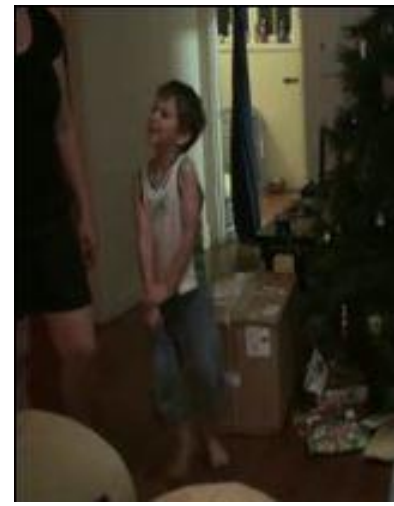

Fig 2c: Mama (L19)

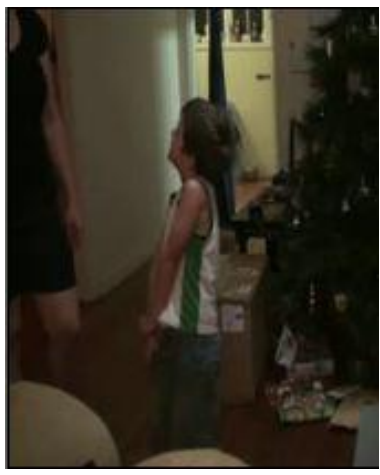

Fig 2d: Can I plea:se do it Mama (L21)

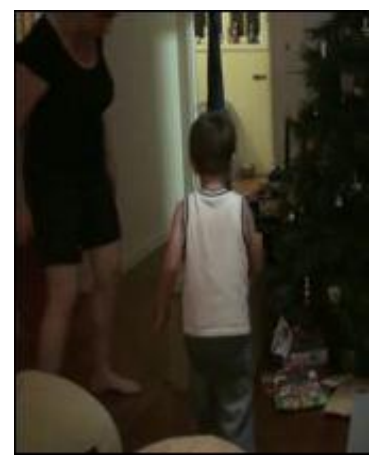

Fig 2e: Can I plea:se do it (L23)

Fredrick has do significant work to achieve the engagement of Nina as his recipient. In order to accomplish this secured recipiency and attain the go-ahead response, Fredrick demonstrates his awareness and consideration of the wider interactional sequence in order to launch his action at a possibly appropriate moment, and makes finely-tuned moves in the pursuit of Nina's engagement.

Firstly, Fredrick launches his initiating action at what seems like an appropriate interactional space, with his request to open the box ('Now can I do it?' at line 15) beginning in transitional overlap with Julian's response to Nina. With Julian's second pair part, the sequence is potentially closed. Nina's movement towards Fredrick suggests disengagement with Julian, and Fredrick appears to be visually tracking Nina, as he begins his request as she enters the camera view (line 15, Fig 
2a). He raises his hand while speaking as a means of making visible his bid for her attention.

While Fredrick's request comes at a point of possible completion of the sequence between Nina and Julian and therefore a possible space for speaker and sequence transition, Nina disattends the request by extending the sequence with Julian with a challenge to his prior turn ${ }^{3}$ (line 18, Fig $2 \mathrm{~b}$ ). She halts her forward trajectory towards the box and turns back towards Julian to show her continued engagement with him. Through Nina's extension of the sequence with Julian (to which Frederick is not a participant), Frederick's bid ends up being sequentially out of place.

Fredrick summons Nina in overlap (line 19, Fig 2c), but Nina also disattends this while bringing her turn to Julian to completion. Fredrick then pursues her engagement by moving into Nina's line of sight, and in line 21 redoes his request, which is upgraded to a plea as marked by Fredrick clutching his hands together and raising his shoulders (Fig 2d), and in the higher pitch used in delivering the request. He also uses 'please' and a turn-final address term, which Wootton (1981) suggests is used in the context of trouble in securing a parent's attention. As Julian responds to Nina's challenge, Nina begins to move back towards the box. With his gaze held on Nina, Fredrick steps backward in unison with her as he reissues his request yet again (line 23). Midway through his turn Fredrick turns back toward the box (line 23, Fig 2e) and the last part of his request trails off in terms of volume and pitch suggesting a treatment of Nina's movement as being on the way to a go ahead, before the permission is verbally granted (line 26).

\footnotetext{
${ }^{3}$ It can be seen that what Nina is challenging here is a presupposition in Julian's turn that the camera can be rewound. By challenging the terms of his answer she is defending the term of her original question in line 11-12 (i.e. that it wasn't a stupid question to ask). This issue of whether the digital camera can be rewound weaves through the whole extended sequence (lines 11-25) and we can see that Nina and Julian have an interactional motivation to extend the sequence despite probably being aware of Fredrick's request, and to prioritise it over Fredrick's request.
} 
The extract illustrates how achieving recipiency in order to get a response to an initiating action is complicated by way of the multiparty context and the matter of concurrent engagements. Although Fredrick's initial request is positioned around a possible transition place and at a moment when the attention of his recipient seems available, Nina disattends it, with the expansion of the prior sequence sequentially deleting the relevance of his request. Consequently, Fredrick has to work to gain the recipiency of Nina and a response to his request. His bids for Nina's recipiency are explicitly managed through the use of a summons (also disattended by Nina), and by moving as much as possible into her line of sight.

\subsection{Suspending recipiency}

While a speaker's bid for recipiency can be disattended, as in Extract 2, an acknowledgement of such a bid does not straightforwardly equate to a right to further engage the recipient. In Extract 3 below, Fredrick's initiating actions are twice treated as being sequentially out of place and are suspended by instructions to wait until the intended recipient is ready. In each case, Fredrick attempts to push forward with his line of action, including once by speaking, whilst maintaining an orientation to the suspension of his activity. As such, in these instances of suspending recipiency (i.e. acknowledging the bid for recipiency and the course of action which the recipiency would move forward while suspending its relevance until a later point in the interaction) we see a distinction between 'the right to speak' and 'the right to engage'; Fredrick is allowed to speak but is explicitly treated as not having the right to engage his father Julian in interaction at these particular moments in the interaction.

The sequence picks up from where extract 1 ended, in which Nina had given Fredrick permission to open another present. While there is a lot of talk in French and inaudible talk, which may make the extract difficult to read, the 'messiness' of the extract gives some indication of the type of interactional 
context within which Fredrick is attempting to initiate action ${ }^{4}$. The images below offer a clearer representation of Fredrick's action through this episode.

\footnotetext{
${ }^{4}$ The tri-lingual nature of this broader interaction adds a further layer of complexity to the methods used in producing and managing multiple interactions and participation frameworks throughout this family interaction. Whereas English dominates in conversations involving all members, the use of French or German marks different participation configurations.
} 


\section{Extract 3}

[WagHDSeg2_XmasTree_2300-2437_Cookbook]

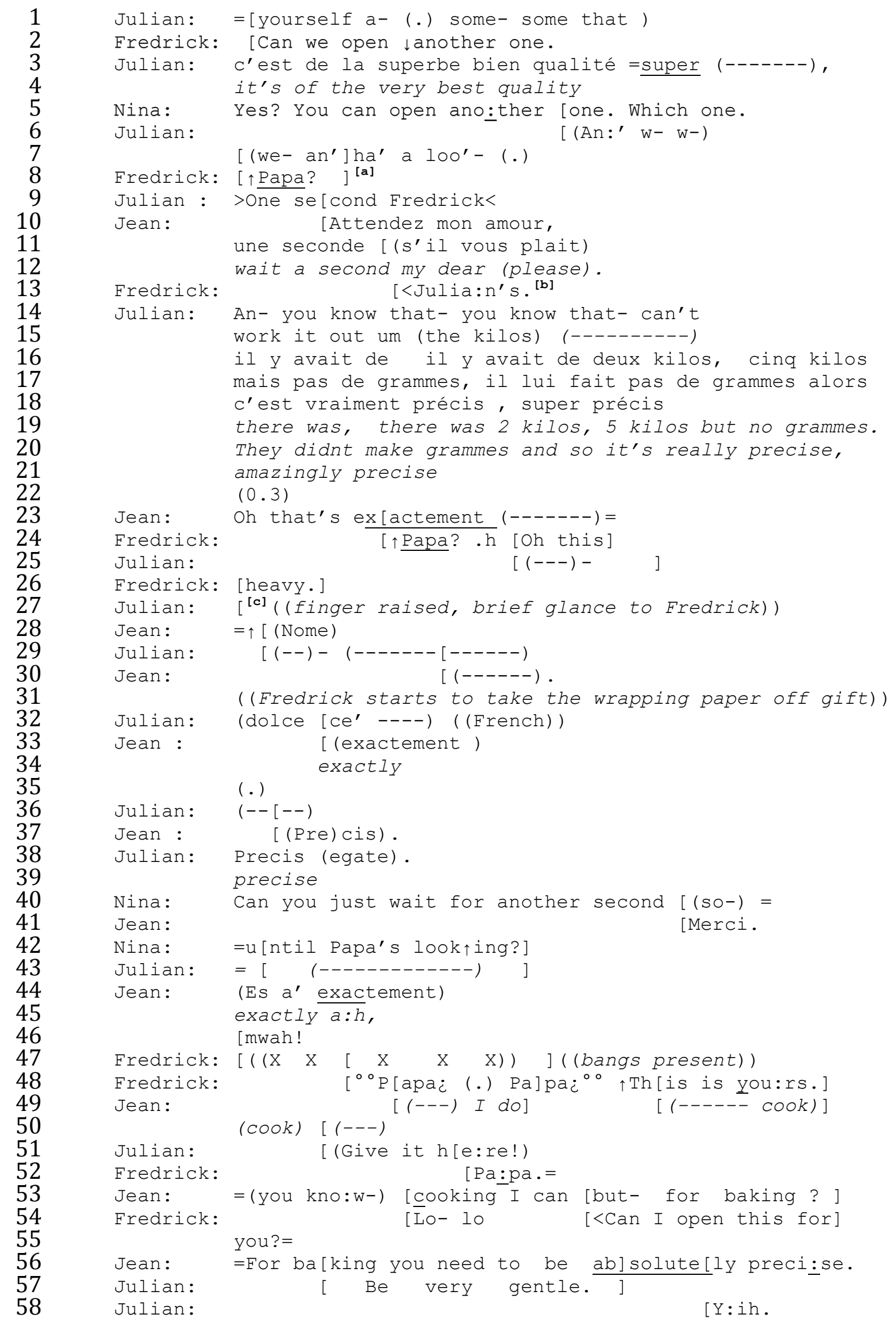




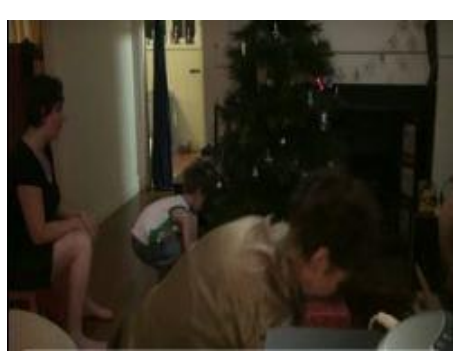

Fig 3a: Papa (L8)

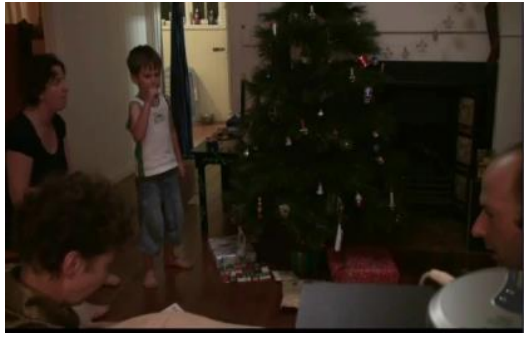

Fig 3b: Julian's (L13)

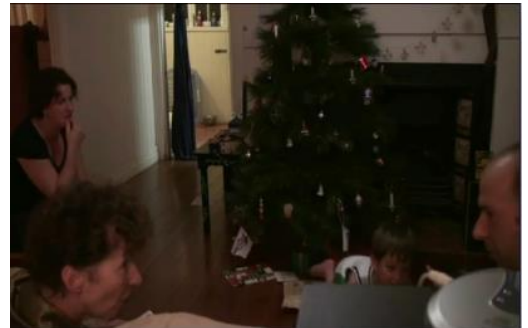

Fig 3c: Raised finger (L27)

To characterise the overall action in this episode, Fredrick seeks and gets permission from Nina to choose another present to be opened and selects one for Julian. He eventually takes the gift over to Julian (during lines 14-23) and gets permission to open it, but the culmination of this sequence and of the course of action which Fredrick is pursuing (the opening of Julian's present) is achieved only through Julian's recipiency and engagement, the relevance of which is twice suspended through instructions to Fredrick to wait (lines 8-11, 24-27).

On the first occasion, Fredrick's summons 'Papa' is responded to with a raised finger and a call to delay for 'one second' by Julian (line 9) and by Jean (lines 10-11), both of whom are engaged in an on-going conversation with each other. Fredrick heeds this instruction in that he does not follow up this summons with another or produce another action which would make a response and a display of engagement from Julian expected. At the same time, however, Fredrick continues to speak and more implicitly to maintain the course of action (the opening of Julian's present) on which he has embarked; he continues to talk in overlap with Jean and announces the selected present as 'Julian's' (line 13). Although Fredrick points to, and looks at, Julian as he says 'Julian's', the announcement is hearable as directed to the room rather than to Julian in particular (in which case it might have taken a form such as 'Papa, this is yours'). Fredrick's turn is neither a sequence-initiating action nor an incursion into Jean and Julian's talk and therefore sidesteps the relevance of the suspensions done by Jean and Julian.

Fredrick then progresses the activity (of Julian opening his gift) non-verbally by carrying the gift over to Julian and placing it by his feet (lines 14-23). He does an emphatic summons 'Papa' at line 24, and then announces 'oh this heavy.' (lines 24-26). Like 'Julian's' at line 13, here Fredrick 's announcement does not demand a response. Unlike the previous announcement, however, this is clearly directed at Julian and allows 
for the possibility of engagement by him. Julian is still, however, clearly talking with Jean and during Fredrick's announcement he flashes him a look and raises his finger (line 27) while returning his gaze to Jean. This micro-gaze by Julian acknowledges that Fredrick has summonsed him and is attempting to engage him at this point, while at the same time his raised finger admonishes Fredrick to suspend his action and bid for engagement until a more interactionally appropriate moment.

For a second time within this extract, therefore, Fredrick's bid for recipiency is responded to with an instruction to wait, and as such the engagement of the adult recipient is suspended until a potential later point in the interaction. As earlier in the extract, Fredrick heeds the instruction at this point and does not pursue recipiency, while at the same time he forwards the course of action he is engaged upon, here by beginning to open the gift by taking the wrapping paper off (line 31). Nina, who is watching Fredrick, asks him to 'wait for another second' until 'Papa's looking' (lines 40/42). In so doing, Nina produces this directive for Fredrick and provides an explicit account that Julian needs to be attending to Fredrick's opening of the gift. As such, Fredrick is here directed once more to suspend his activity, although here the activity is the physical opening of a present rather than a bid for the recipiency of Julian.

Fredrick finally manages to gain Julian's recipiency and his engagement, with Julian explicitly displaying this in line 51, turning to Fredrick and saying 'give it here', referring to the gift that Fredrick has been trying to bring to his attention. Fredrick's successful bid for Julian's recipiency here can be seen to be carefully placed and managed. In line 44 Jean seems to bring the encounter with Julian to a possible close with her praise, 'Es a' exactement' and brings her hands to her face with a 'mwah' kissing noise displaying pleasure and gratitude at the gift. Fredrick demonstrates his monitoring of Jean's activity to identify an appropriate place to complete his 'waiting' and rebid for Julian's attention. He keeps his gaze on Jean (Fig 3d) and at the instant she turns to Nina while continuing to talk, he begins to bang the gift, again inviting recipiency without being seen to explicitly bid for it, and then summons Julian sotto voce with 'Papa' (line 48). 
The combination of the banging and sotto voce voice is less direct than a loud and explicit bid for recipiency, and treats this position as a potentially problematic moment to launch the action. Jean is still talking; but her talk does seem to be directed at Nina, suggesting the close of the interaction with Julian and thus potentially a time when Julian could 'look'. Fredrick's caution here seems warranted given that he has had his bids for recipiency suspended twice already, despite his apparent eagerness to proceed with the gift opening. Using these particular methods to mobilise Julian's recipiency suggests some orientation to limited rights to engage Julian at this point and an understanding that recipiency is contingent upon how Julian deals with his concurrent engagements.

The summons is, finally, responded to with Julian's 'give it here' (line 51) after Fredrick announces 'this is yours'. However, Fredrick had throughout been concerned not with passing the gift to Julian but opening it for him. He requests permission to do this (lines 54-55) which is granted with the caution to 'be very gentle'. The gift is then fully opened and a new sequence of admiration and gratitude is begun (not shown in the transcript). The course of action initiated by Fredrick is thus finally carried out, but only after this extended seeking and pursuit of Julian's recipiency and go-ahead for the action of permission to open the present.

In Extract 3, therefore, we see an explicit orientation to a child's (Fredrick's) limited rights to engage in interaction at a particular point in time. By twice suspending the relevance of Fredrick's bids for recipiency and engagement, Julian and Jean, who are currently engaged in conversation with each other, display that while they have registered Fredrick's bids, they area treating them as inapposite at this point within the interaction. This explicit orientation to Fredrick's lack of rights to engage another at this point can be contrasted with the disattention shown by Nina to Fredrick's bids to gain her recipiency in Extract 2, where any such orientation was implicit in the disattention and might be accounted for, at least potentially, by reference to other causes, such as a failure to register that Fredrick had spoken at these points.

Responding to a child's bid for recipiency by disattenting it or suspending its relevance will also be seen in the final extract, Extract 4. In this extract, as in Extracts 2 and 3, it 
can be seen that Fredrick finally achieves recipiency following various means of pursuing it. It will be these methods of pursuing recipiency which we will particularly focus on in this example, while also highlighting further instances of adults' disattending or suspending recipiency in relation to the child's bit to engage them in interaction.

\subsection{Pursuing recipiency}

In Extract 4, Fredrick's bids for recipiency are twice suspended by being treated as inapposite at this point in the interaction. In line 2 Frederick is told by Jean to 'wait'; she sanctions his bid to engage Nina in a course of action (he requests permission to open an envelope in line 1) with the account that she and Julian are 'listening' (lines 2-4) to Nina, who has begun to read out a Christmas card from her boss ${ }^{5}$. As in Extract 3, then, Fredrick's course of action is suspended - through the suspension of the recipiency of the adult who would forward that course of action - pending completion of another inprogress activity. In response, Fredrick then does 'waiting' by pacing back and forth across the floor during Nina's extended turn reading the card contents aloud.

In line 16, following the hearable end of Nina's reading out of the card (lines 12-13) and Jean's response to the card reading in the form of a positive assessment of the card's message (line 15) Fredrick again makes a bid to mobilise recipiency. Here it is not by relaunching his earlier request but rather by producing a different type of initiating action - a pre- announcement, 'but guess what guys?' (line 16) ${ }^{6}$. This bid for recipiency is disattended (see below). When Fredrick produces a further bid for recipiency (lines 22

\footnotetext{
5 With the account 'we're listening' Jean references herself and Julian as ratified listeners and makes relevant Nina's position as 'current speaker'. Fredrick is excluded from the group as neither a speaker nor a listener, which positions him as a 'cross-member' (Sacks, 1995; see also Chapter 7 in Butler, 2008) to the adults - not an active participant in the interaction. Arguably, this is an instance where Fredrick's membership in the category of 'child' is made relevant for his participation in the interaction.

6 This pre-announcement appears to be already foreshadowing Fredrick's announcement about the remaining presents under the tree, 'those are for me' in lines 57-58, rather than constituting a further bid for recipiency and engagement in relation to the opening of the card which he was requesting in line 1. This shift to a focus on the presents under the tree may have been prompted by the fact that he glances at these presents while waiting for Nina to finish reading out her card.
} 
and 25-26) Julian suspends the relevance of this bid with the admonishment 'one second Fredrick' in line 28.

\section{Extract 4}

[WagHDSeg2_Xmas Tree_2500_Guess what]

Fredrick: ${ }^{\wedge}$ Can I [open?-

Jean: [Attend cheri. No we're=

wait darling

$=$ li:stening. $=W^{\prime}$ re listening. $=($ En $)$ C'est bon .

$(0 . \overline{3})$

Nina : s:upport, patience, loyalty and peer input.

(0.9) You have done an ama:zing journey since

you joined the science team. I'm tru:ly

grateful and honored to work with yoü:,

look forward to working mo:re, (.) in

two thousand an' ten. ${ }^{[a]}(0.3)$ A: lways Ella.

=^Pee es(.) ${ }^{[b]}$ thank :- thanks too for the

friendship. [c]

$(0.4)$

Jean: ‘Isn't ${ }^{[d]}$ that w[onderful

Fredrick: ((raises finger)) [But guess whalt ^gu:ys?

Nina: $\quad$ A And funnily enough

((Fredrick raises hand and keeps it held aloft))

i- $(0.2){ }^{6}$ without reading this, (0.2) I've

Jean: written something very similar in her card.

Jean: 
59 Julian: [(Fredrick) $i]$

$60 \quad(0.7)$

61 Julian: (-) $[>$ look $<$. 
Focusing on Fredrick's bids for recipiency which are disattended, we will first examine the pre-announcement produced in line 16. This pre-announcement is disattended in that none of the adults registers or responds to it (for example, in the form of a 'go-

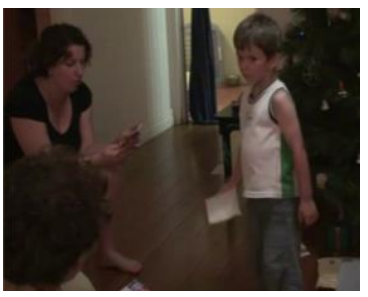

Fig 4a: two thousand an' ten. [a] (L11)

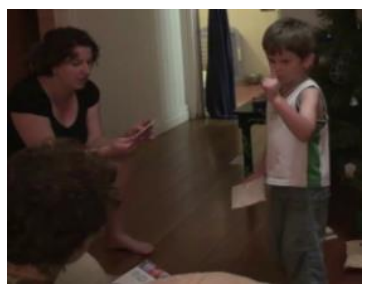

Fig 4b: Pee es (.) [b] thank:- (L12)

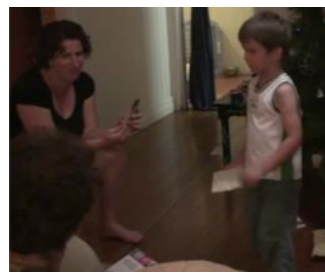

Fig 4c: thanks too for the friendship.[c] (L13)

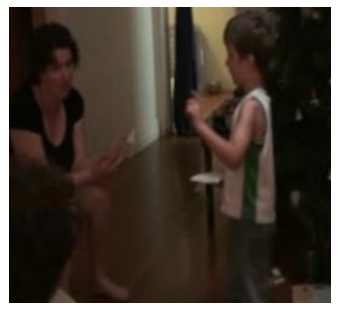

Fig 4d: Isn't [d] that wonderful (L15)

ahead' (Schegloff, 2007) such as 'what?' which would forward the course of action which Fredrick is attempting to launch here). Instead, Nina continues to talk to the other two adults about the ongoing topic of the card from her boss (lines 17-19).

This disattention occurs even though Fredrick's actions in launching and producing his turn are precision placed in terms of identifying and making use of the transition places apparent in the closing of Nina's reading-out-the-card-aloud turn (lines 12-13, see Fig 4a-d). He raises his finger as an attention-getting pre-enactment (Streeck, 1995) before verbally making a bid for recipiency with his turn 'but guess what guys' at line 16 . The 'but' here seems to be used as a 'resumptive but' (Mazeland and Huiskes, 2001) which ties his talk to prior talk. The pre-announcement deploys a formulation that Sacks (1995) suggests is a strategy by which children work towards securing a third position slot in that it projects some form of announcement or news to follow after a go-ahead from the recipients. In this instance, Fredrick addresses all adults through the collective reference 'guys' - which attempts to position all as recipients. While Fredrick seems to have been acutely tuned in to the end of Nina's reading, he has, however, perhaps failed to take into account the conditional relevance of receipt and assessment by the adults following Nina's reading out of the card's contents. The verbal initiation of his action ends up overlapping Jean's positive assessment, and this assessment is then followed by further talk by Nina about the card. 
Having positioned all three adults as potential recipients with 'guys', Fredrick treats it as necessary to gain the recipiency of all three before he produces the announcement (lines 61-62) which has been foreshadowed by the pre-announcement first produced in line 16. First, he continues to orient towards all three together. As Nina continues to talk about the card from her boss, Fredrick raises his hand to make a bid for a turn (line 18). This non-verbal pursuit of recipiency is designed to get attention and invites a go-ahead to speak. It demonstrates Fredrick's recognition of his limited rights to talk right now, due to the adult talk extending the sequence initiated by Nina. With no display of recipiency by any adult, Fredrick produces further requests, which are also unsuccessful in engaging any of the adults (lines $23,26-7$ ).

With his bids for recipiency thus far disattended or suspended, Fredrick then employs a different method of mobilising recipiency, selecting Nina as a sole recipient by whispering something to her while she is observably listening to Jean (line 31). With this method Fredrick designs a concurrent engagement that is relatively difficult to disattend. Whispering to one party is a means by which an action can be bracketed off from the collective interaction in a parallel and less competitive way. Nina gives an unclear audible response that seems to serve as a go-ahead to Fredrick, as the card sequence is brought to a close with the closing implicative idiomatic-like formulations from Jean and the laughter by Julian (lines 34-38). During this closing, Fredrick restarts his initiating action - the preliminary 'Guess what guys' - two further times (lines 39, 41-44), this time with raised volume and pitch. Fredrick's gaze and body orientation display that these utterances are directed towards Jean and Julian (the two adults who have not yet displayed their recipiency to him). The first of these bids is disattended by the two recipients as Julian extends his laughter in an exaggerated and playful way, for what purpose is unclear (line 40). After a second cut-off start (line 41), however, Jean aligns herself as a recipient for Fredrick, giving him a go-ahead to pursue his line of action (line 42). Julian though is still not aligned as a recipient, and he upgrades his laughter even more (line 43), one again disattending Fredrick as he re-launches his preannouncement (line 44). 
At this point, Fredrick focuses his attention on Julian, the one remaining adult who has not yet displayed recipiency. As Julian laughs, Fredrick reprimands him with a forceful sounding 'Papa!' and moves towards him with the 'stop' gesture. In doing so, he treats Julian's occupation of the floor as inappropriate and unwarranted, and demonstrates his recognition of his right to be next speaker and Julian's responsibility to attend to him, as the other two adults now are doing. So, whereas previously Fredrick had been the one 'interrupting' - here, Julian is accorded that role. Following this, Fredrick gets his turn in the clear - again repeating 'guess what' (line 47). In this instance, however, he does not leave a space for a second position turn to get the third slot; the directive 'look', and then the pointing at the presents with his foot follows straight on from the 'guess what' (line 47). As Jean counts the presents in French Fredrick delivers the projected upshot of his invitation to notice: an announcement that the remaining presents are for him (lines 54-55).

\section{CONCLUSION}

Conversation analytic research has highlighted and explored how certain actions (e.g. requests) produced in certain sequential positions (e.g. as first pair parts of an adjacency pair) make it normatively expectable that a type-fitted second pair part response will be produced by another speaker (Schegloff and Sacks, 1973; Schegloff, 2007). The initial expectation will be that it is the recipient addressed by the first pair part who will produce the second pair part. This pattern of mobilising a response from a recipient is massively present throughout talk-in-interaction (see Stivers and Rossano, 2010, for further discussion). As such, predominantly recipiency does not have to be sought, or mobilised, as a separate action; it is mobilised implicitly as part of the act of mobilising a response from a recipient through producing a certain action with a certain (grammatical, prosodic etc.) form. At the same time, there will be occasions where a speaker may wish to act specifically to engage the recipiency of a co-participant as a separate action in interaction. The summons is an action utilised for this purpose, typically produced as a preliminary to a further action (e.g. an announcement or a request), with that subsequent action contingent on a go-ahead from the recipient, signalling alignment with the summoner (Schegloff, 2007; on other types of preliminaries see Schegloff, 1980 and Terasaki, 2004). 
Here we have examined practices of mobilising recipiency employed by a five year old child, Fredrick, in multi-party interactions containing three adults; his mother, father and grandmother. Reconceptualising the notion of 'rights to speak' in terms of 'rights to engage' we have examined methods by which the child attempts to mobilise recipiency, how these attempts are responded to by the adults in the interaction, and how the child pursues recipiency when it is not gained in the first instance. In each of the four extracts analysed here, the child uses a summons (Extract 1, line 4; Extract 2, line 19; Extract 3, lines 8, 24, 48; Extract 4, line 45) in an attempt to gain the attention and recipiency of an adult. As well as summonses, another type of pre-sequence used is a pre-announcement i.e. 'guess what (guys)' in Extract 4 (lines 16, 39, 41-44, 47). This also functions here to gain the recipiency of the adults as a preliminary to an announcement or telling (cf. Sacks' (1972: 343) examples of 'You know what, Daddy?' and 'You know something, Mummy?').

It is a notable feature of these data that the child's attempts to mobilise recipiency are regularly not positively aligned with by an adult, either due to the adult disattending the child's utterance (whether through not registering it or choosing to ignore it is an issue which will not concern us here) or by suspending its relevance and the forwarding of the course of action through an injunction such as 'wait'. It is following this lack of positive alignment and encouragement to forward the course of action that the child regularly pursues engagement either with another first pair part or an explicit bid for recipiency (see, for example, Extract 2, lines 15, 19, 21 and 23; and Extract 3, lines 2, 8, $24,48)$.

In relation to the notion of children's 'restricted rights to speak', we have here reconceptualised this in terms of 'restricted rights to engage'. One way in which these restricted rights are evident at certain points in the interaction is where an adult responds but explicitly suspends Fredrick's right to gain their recipiency and engage them in interaction through suspending the relevance of the recipiency bid with an injunction such as to 'wait' (Extracts 3 and 4). It also appears to be evident, however, where adults disattend Fredrick's recipiency bids and other actions. Fredrick himself appears to orient towards his restricted rights to engage at certain points not only 
through his recurrent use of pre-sequences, in particular summonses, but also through the form of some of his bids for recipiency, such as raising his hand (Extract 4, line 18), an apparently weaker recipiency bid than a spoken summons, since it does not vocally compete with other turns (see also Extract 3, line 48).

These restricted rights to engage an adult in interaction appear to be part of a wider pattern evident in these data of what might be thought of as the child's restricted rights of action, where 'action' refers to both the social actions produced in talk (e.g. requests etc.) and physical actions, such as opening a present. It is possible in these data to gain some indication of the amount of interactional work which the child has to do in order to get adults aligned with him in order that a particular desired activity will get carried out. For example, a request for permission by Fredrick to carry out an action (here, to open a present or card) is observable in all four of the extracts (e.g. Extract 1, line 8; Extract 2, line 15; Extract 3, line 2; Extract 4, line 1). In each case, gaining the go-ahead from one or more adults in the form of permission to open the present/card is not straightforward, with Fredrick having to make more than one bid to secure the attention of the adult(s), either before the request has been produced (e.g. Extract 1), or after it has been produced but has not gained a positive response, due for instance to the adult disattending it (e.g. Extract 2).

In interactional data such as these, it is possible to see how an orientation to a child's restricted rights may be evident in both the adults' and the child's behaviour. This raises questions about the relevance Frederick's membership as a child has for what goes on in these extracts, and in adult-child interaction more generally. The notion of ethnomethodological indifference holds that analysts should 'bracket off' the relevance of common sense understandings about members in terms of describing what they do (Garfinkel and Sacks, 1970; Garfinkel and Weider, 1992). Conversation analysts generally avoid explanations of interactional practices that rely on speakers' membership in categories such as gender or ethnicity, or which draw on preconceived understandings about authority in institutional interaction. Adopting this position in relation to children's interaction means that one should put aside the relevance of children as children in the analytic phase, and 'bracket off childliness' (Butler, 2008; Butler and Fitzgerald, 2010). 
The practices we observe Frederick use to mobilize recipiency are not restricted to children; adults also use preliminaries such as 'guess what' or summonses prior to launching actions. These methods are effective for both gathering collective attention and initiating a new action sequence in the context of potentially multiple forms of engagement. Both the methods and participant responses may display or invoke an orientation to members' (limited) rights to speak, engage, or launch action, and such rights can be treated as interactionally situated rather than resting on age as an explanatory resource ${ }^{7}$. Rights to speak, then, are managed in terms of sequence and action, rather than independently allocated by virtue of speaker's social relations.

However, we may not want to let go of the relevance of category membership entirely. It is a commonsense notion that in terms of participation and involvement, children are different from adults. Whilst the boundaries between the categories of baby, child, adolescent, young adult and adult are fuzzy, people tend to (flexibly and locally) use these memberships in both producing and making sense of social action. This is an empirical issue, with development, stage of life and relationships played out in actual interactions (Forrester, 2002; Forrester and Reason, 2006; Butler and Fitzgerald 2010). Furthermore, children are, commonsensically and essentially, developing their competencies in taking part in everyday interaction. Children have fewer experiences and resources to draw on in managing their participation and are continually developing the skills of social and cultural membership (Schegloff, 1989).

The adults' orientations to Frederick's limited rights are part of his socialization into taking part in multi-party interactions. We see that there is much Frederick is competent in: monitoring the engagement and attention of other people, positioning an

\footnotetext{
${ }^{7}$ In terms of participant responses, adults may be less likely to put another adult's bid to speak 'on hold' through verbal or non-verbal means than we observe in this adult-child data. Certainly one observes adults putting other adults on hold in contexts such as televised debates and interviews, or two-party interactions in which one person is chairing a group discussion. Notably, these two obvious examples involve institutional contexts with distinctive application of the rules for turn-taking and institutionally shaped and shaping memberships. In less institutional contexts such practices may be done in ways that mark the actions as delicate or dispreferred, which a reviewer suggests is not the case in this data (although one might argue that the use of terms of endearment in bids to put Frederick 'on hold' may attend to the potential delicate aspects of the action). However, given the relative lack of research on multiparty interaction between adults in everyday contexts, whether or not adults would treat other adults in the way that a child is responded to in this data is something that remains open for empirical examination.
} 
initiating action at a precise moment in the course of an ongoing interaction, and seeking and pursuing the engagement of others. Yet these bids to gain recipiency and to launch a new action can fail in regular ways; for instance, in not recognising that an extended assessment sequence is not yet complete (Extract 3). What is most noticeable about these sequences is the extent to which Frederick persists in his pursuit of recipiency. The adults' lack of displayed recipiency and instructions to 'wait' are methods through which an understanding of how to launch new actions in the context of multiparty interaction will be developed. Yet, in each case, 'limited rights' is a locally produced and situated phenomenon - it is something that plays out in the detail of actual interactions. These rights are also co-produced, with an orientation to limited rights coming not only from the adults, but from the child himself as he calibrates his efforts to launch his actions in response to the blocks and suspensions he faces. The focus on seeking and pursuing recipiency through the use of preliminaries and other practices is suggestive of the child's own orientation to these limited rights.

Bracketing off structural accounts of child participation in family interaction allows for a more nuanced account of the interactional bases for failed attempts at 'speaking' by a child. In addition to revealing more of the turn-taking practices children are socialised into, it also offers new understandings about adult-adult interaction. Observation of the early stages of generic practices for taking part in social interaction can develop our understanding of the methods by which everyday social life is organised. The notion of mobilizing recipiency as a pre-condition for launching action in the context of multiparty interaction is so salient here because it is problematic in some ways. Over time, and with experience and practice and the type of sanctioning and constraints younger members deal with, mobilising recipiency is accomplished in a much smoother fashion. Nevertheless, the foundations of this practice are visible here, in the early efforts of a five year old managing this work in a family Christmas celebration.

\section{Acknowledgements}

An earlier version of this paper was presented at the Loughborough University Conversation Analysis Day in December 2010. The paper has benefitted from comments and discussions by members of the Loughborough University Discourse and Rhetoric 
Group, and by attendees at the Conversation Analysis Working Group Seminar at the University of California Los Angeles in March 2011. We thank Derek Edwards, and two anonymous reviewers for their insightful comments on the paper.

\section{References}

Aronsson, Karin, Cekaite, Asta, 2011. Activity contracts and directives in everyday family politics. Discourse Studies 22, 137

Aronsson, Karin, Gottzen, Lucas, 2011. Generational positions at a family dinner: Food morality and social order. Language in Society 40, 405-426.

Butler, Carly W., 2008. Talk and Social Interaction in the Playground. Aldershot: Ashgate.

Butler, Carly W., Fitzgerald, Richard, 2010. Membership-in-action: Operative identities in a family meal. Journal of Pragmatics 42 (9), 2462-2474

Egbert, Maria M. 1997. Schisming: the collaborative transformation from a single conversation to multiple conversations. Research on Language and Social Interaction $30,1-51$.

Ervin-Tripp Susan M, Mitchell-Kernan Claudia, 1977. Introduction. In Ervin-Tripp, S.M., Mitchell-Kernan, C. (Eds.), Child Discourse. New York: Academic, pp. 1-23.

Ford, Cecilia E, Stickle, Trini, 2012. Securing recipiency in workplace meetings: Multimodal practices. Discourse Studies 11, 30.

Forrester, Michael A., 2002. Appropriating cultural conceptions of childhood: Participation in conversation. Childhood 9(3), 255-276.

Forrester, Michael. A., Reason, David, 2006. Competency and participation in acquiring a mastery of language: a reconsideration of the idea of membership, The Sociological Review 54/3, 446-66

Forrester, Michael, A., 2010. Ethnomethodology and adult-child conversation: Whose development? In: H. Gardner, M.A. Forrester (Eds.), Analysing Interactions in Childhood: Insights from Conversation Analysis. Chichester: Wiley-Blackwell, pp 42-58.

Garfinkel, Harold, Sacks, Harvey, 1970. On formal structures of practical action. In: J. C. McKinney, E.A. Tiryakian (Eds.), Theoretical Sociology: Perspectives and Developments. New York: Appleton-Century-Crofts, pp 338-366.

Garfinkel, Harold, Wieder, D. Lawrence, 1992. Two incommensurable, asymmetrically alternate technologies of social analysis. In G. Watson, R.M. Seiler (Eds.). Text in Context: Contributions to Ethnomethodology. Newbury Park: Sage Publications, pp 175-206. 
Goffman, Erving, 1961. Encounters: Two Studies in the Sociology of Interaction - Fun in Games \& Role Distance. Indianapolis, Bobbs-Merrill.

Goffman, Erving, 1981. Forms of Talk. Oxford, England: Blackwell.

Goodwin, Charles, 1981. Conversational organization: interaction between speakers and hearers. New York: Academic Press

Goodwin, Charles, 1986. Gesture as a resource for the organization of mutual orientation. Semiotica 62, 29-49.

Hutchby, Ian, 2005. Children's talk and social competence. Children and Society 19 (1), 66-73.

Hutchby, Ian, 2010. Feelings-talk and therapeutic vision in child-counsellor interaction. In: H. Gardner, M.A. Forrester (Eds.), Analysing Interactions in Childhood: Insights from Conversation Analysis. Chichester: Wiley-Blackwell, pp 146-162.

Jefferson, Gail, 2004. Glossary of transcript symbols with an introduction. In: G. H. Lerner (Ed.), Conversation Analysis: Studies from the First Generation. Amsterdam: John Benjamins, pp. 13-31.

Mazeland, Harrie, Huiskes, Mike, 2001. Dutch but as a sequential conjunction. Its use as a resumption marker. In: M. Selting, E. Couper-Kuhlen (Eds.), Studies in Interactional Linguistics. Amsterdam: John Benjamins, pp. 141-169.

O’Reilly, Michelle, 2006. Should children be seen and not heard? An examination of how children's interruptions are treated in family therapy. Discourse Studies 8, 549-566.

Rae, John, 2001. Organizing Participation in Interaction: Doing Participation Framework. Research on Language \& Social Interaction, 34(2), 253 - 278.

Sacks, Harvey, 1972. On the analyzability of stories by children. In: J.J. Gumperz, D. Hymes (Eds.), Directions in Sociolinguistics: The Ethnography of Communication. New York: Rinehart \& Winston, pp. 325-345.

Sacks, Harvey, 1995. Lectures on Conversation (2 Vols.). G. Jefferson (Ed.) Edited by Gail Jefferson with introductions by Emanuel A. Schegloff. Oxford: Basil Blackwell

Sacks, Harvey, Schegloff, Emanuel A., Jefferson, Gail, 1974. A simplest systematics for the organization of turn-taking in conversation. Language 50,(4), 696-735.

Schegloff, Emanuel A., 1980. Preliminaries to preliminaries: "Can I ask you a question?"', Sociological Inquiry 50, 104-52.

Schegloff, Emanuel A., 1989. Reflections on language, development, and the interactional character of talk-in-interaction. In: M.H. Bornstein, J.S. Bruner, eds. Interaction in human development. Hilsdale, N.J.: Lawrence Erlbaum, pp 139-53. 
Schegloff, Emanuel A., 1995. Parties and talking together: Two ways in which numbers are significant for talk-in-interaction. In: Paul ten Have, George Psathas (Eds), Situated order: Studies in the social organization of talk and embodied activities. Washington, D.C.: University Press of America, pp 31-42

Schegloff, Emanuel A., 1996a. Turn organization: one intersection of grammar and interaction. In: In: Ochs, E., Emanuel A. Schegloff, S.A. Thompson (Eds), Interaction and Grammar. Cambridge: Cambridge University Press, pp 52-133

Schegloff, Emanuel A., 1996b. Some practices of referring to persons in talk-in-interaction: a partial sketch of a systematics. In: B. Fox (Ed.), Studies in Anaphora. Amsterdam: John Benjamins, pp. 437-485.

Schegloff, Emanuel A., 2007. Sequence Organization in Interaction: Volume 1: A Primer in Conversation Analysis. Cambridge: Cambridge University Press.

Schegloff, Emanuel A., Sacks, Harvey, 1973. Opening up closings, Semiotica 8, 289-327.

Stivers, Tanya, Rossano, Federico 2010. Mobilizing response. Research on Language and Social Interaction 43 (1) 3 - 31

Streeck, Jurgen, 1995. On Projection. E. Goody (Ed.). Interaction and Social Intelligence Cambridge: Cambridge University Press, pp 84-110.

Terasaki, Alene K., 2004. Pre-announcement sequences in conversation. In: Gene H. Lerner, ed. Conversation Analysis: Studies from the first generation.

Amsterdam/Philadelphia: John Benjamins, pp 171-223.

Wootton, Antony J., 1981. Children's use of address terms. In: Peter French, Margaret MacLure, eds. Adult-child conversation. New York: St. Martins: 142-58 